\title{
Differential expression of neurogenins and NeuroD1 in human pituitary tumours
}

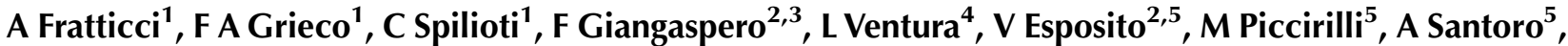 \\ A Gulino $^{2,3}$, G Cantore ${ }^{2}$, E Alesse ${ }^{1}$ and M L Jaffrain-Rea ${ }^{1,2,6}$ \\ ${ }^{1}$ Department of Experimental Medicine, University of L'Aquila, Via Vetoio, Coppito 2 - 67100 L'Aquila (AQ), Italy \\ ${ }^{2}$ Neuromed Institute, IRCCS, Pozzilli, Via Atinense 18, 86077 Pozzilli (IS), Italy \\ ${ }^{3}$ Department of Experimental Medicine and Pathology, University 'La Sapienza', Policlinico Umberto $1^{\circ}$, Viale dell'Università, 00161 Rome (RM), Italy \\ ${ }^{4}$ Pathology, S Salvatore Hospital, L'Aquila, Coppito, 67100 L'Aquila (AQ), Italy \\ ${ }^{5}$ Departments of Neurological Sciences, Policlinico Umberto $1^{\circ}$, Via Regina Margherita, 00161 Roma (RM), Italy \\ ${ }^{6}$ Fondazione 'Carlo Ferri', Via E. Riva 42, 00015 Monterotondo (RM), Italy \\ (Correspondence should be addressed to $M L$ Jaffrain-Rea; Email: jaffrain.ml@libero.it)
}

(A Fratticci and F A Grieco contributed equally to this work)

\begin{abstract}
Basic helix-loop-helix (bHLH) transcription factors are involved in neuroendocrine cell growth and differentiation. Though NeuroD1 is viewed as corticotroph specific, its overexpression in non-corticotroph pituitary adenomas (PAs) may reflect the activation of molecular pathways involving other bHLH factors, like neurogenins. To search for neurogeninNeuroD1 molecular pathways in the human normal and tumoural pituitary. Fifty-one PAs - 22 clinically non-secreting (CNS) and 29 secreting respectively - and normal human pituitaries (NP) were studied for NeuroD1 and neurogenins (Ngn1, Ngn2 and Ngn3) gene expression by RT-PCR and quantitative real-time RT-PCR (qRT-PCR). Immunohistochemistry for Ngn2/3 was performed in some cases. NeuroD1, Ngn2, Ngn3 and Ngn1 were observed in up to 84 3, 76 5, 30.4 and $9 \cdot 1 \%$ of PA respectively, only NeuroD1 and Ngn 2 being frequently overexpressed when compared with NP. Whereas
\end{abstract}

NeuroD1 expression was higher in corticotroph and CNS adenomas $(P=0 \cdot 0001$ versus Pit-1-dependent PA), Ngn2 expression was higher in secreting PA, especially in Pit-1dependent PA $(P=0.007$ and $P=0.0006$ versus CNS respectively). Pit-1-dependent $\mathrm{PA}$ which received pre-operative pharmacological treatment expressed higher Ngn2 levels than untreated cases $(P=0 \cdot 025)$. Nuclear Ngn2 was observed in NP and in most PA, especially ACTH- and GH-secreting adenomas. Nuclear Ngn3 was observed in a minority of secreting PA. Ngn2 is normally expressed in the anterior pituitary and frequently expressed in PA, but does not account for NeuroD1 overexpression where present. Owing to their low and inconstant expression, the biological significance of $\mathrm{Ngn} 1 / 3$ in the adult pituitary is uncertain.

Journal of Endocrinology (2007) 194, 475-484

\section{Introduction}

Basic helix-loop-helix (bHLH) transcription factors play a fundamental role in the ontogenesis of highly differentiated cells, especially during neurogenesis, myogenesis and haemopoiesis (Massari \& Murre 2000), and proneural bHLH are involved in the development of neuroendocrine cells (Lanigan et al. 1998, Edlund 1999, Ma et al. 1999, Ito et al. 2000). Basic HLH proteins can act early during ontogenesis, as determinating factors which recruit cells to a specific progenitor pool, or later as final differentiating factors. Though bHLH factors have been observed in the anterior adult pituitary (Jackson et al. 1993), studies on the transcriptional control of pituitary development have mainly focused on homeodomain factors acting since early embryogenesis, and factors essential for cell-specific differentiation like Pit1 in prolactin/growth hormone/thyrotrophin (PRL/GH/TSH)secreting cells and Tpit/Tbx19 in corticotrophs respectively (Dasen \& Rosenfeld 2001, Lamolet et al. 2001). The possible role of bHLH proteins has been progressively emerging during the last decade, essentially involving members of the proneural family NeuroD1/Math/neurogenins. NeuroD1 is currently viewed as a corticotroph-specific factor, which plays a dispensable role in corticotroph differentiation and collaborates with Pitx1 and T pit to regulate proopiomelanocortin gene expression (Poulin et al. 1997, 2000, Lamolet et al. 2004). Though neurogenins (Ngn1/NeuroD3, Ngn2 and Ngn3) induce NeuroD1 expression in the nervous system/neural crest (Ngn1 and Ngn2; Ma et al. 1999) and in gastroenteropancreatic neuroendocrine cells (Ngn3; Huang et al. 2000), only Ngn2 has been observed in the developing pituitary yet, though apparently unrelated to corticotroph differentiation 
(Lamolet et al. 2004). Finally, while the human homologue of Drosophila achaete-scute ASH1 has been identified in the normal adult pituitary (Ferretti et al. 2003), there is recent evidence that the corresponding zebrafish homologue ascl1 plays a fundamental role in pituitary development (Pogoda et al. 2006). Thus, there is increasing interest in elucidating the role of bHLH factors in pituitary development, function and diseases.

A body of literature has been dedicated to the possible role of bHLH proteins in tumorigenesis over the last 15 years (Semenza 2002, Ivanova et al. 2005, Kwok et al. 2005), but few data on proneural bHLH expression are available. NeuroD1, ASH1 and Ngn1/NeuroD3 can be expressed by primary neuroectodermal tumours, with Ngn1 expression associating with a metastatic potential in medulloblastomas (Rostomily et al. 1997). In contrast, overexpression of NeuroD1 or Ngn1 induces differentiation of neuroblastoma cells (Cho et al. 2001, Kim et al. 2002). In human pituitary tumours, NeuroD1 is expressed by corticotroph adenomas and also by most non-secreting adenomas (Oyama et al. 2001, Ferretti et al. 2003), with a possible overexpression in this latter group (Ferretti et al. 2003), suggesting a possible activation of some bHLH molecular pathway in these tumours. The expression of neurogenins in PA has not been studied yet.

The aim of this study was to look for neurogenins as putative members of the bHLH proteins identified in pituitary tumours (Jackson et al. 1993), to analyse possible neurogenins-NeuroD1 molecular pathways in pituitary tumour cells and to evaluate their possible prognostic value if present.

\section{Material and Methods}

\section{Patients and samples}

Surgical biopsies of 51 pituitary adenomas (PAs) were collected at the time of surgery, most of them in an RNAlater solution (Qiagen), and successively stored at $-80^{\circ} \mathrm{C}$ until processing. Four normal adult pituitary glands (seven fragments) were collected within 48 -h post-mortem in patients who died from non-endocrine diseases and snapfrozen - in three cases, half pituitary was formalin-fixed and paraffin-embedded for histological purposes. The study was approved by the local ethical committee. PA included 22 clinically non-secreting (CNS) and 29 secreting adenomas (13 GH-, 7 PRL-, 7 adrenocorticotrophin (ACTH)- and 2 TSHsecreting adenomas respectively). Tumour volume and invasiveness were systematically recorded on the basis of neuroradiological criteria and intra-operative findings, and classified according to Wilson's criteria (Wilson et al. 1984). Most were macroadenomas ( $n=47), 30$ were invasive and 11 were recurrent respectively. Among patients with secreting adenomas, 12 had received pre-operative pharmacological therapy consisting of somatostatin analogues $(n=8$, including six GH-secreting and two TSH-secreting PAs respectively) or dopamine agonist therapy $(n=3$, two PRL-secreting and one
GH-secreting respectively). PAs were routinely characterised by immunohistochemistry for hormone secretion, using polyclonal anti-PRL, anti-GH, anti-follicle-stimulating hormone (anti-FSH), anti-luteinizing hormone (anti-LH), anti-ACTH antibodies (Orthodiagnostic Systems, Raritan, NJ, USA) and the streptavidin-biotin peroxidase method (Dako Cytomation, Milan, Italy). CNS adenomas were then classified into null cell $(n=14), \mathrm{FSH} / \mathrm{LH}-$ secreting $(n=5)$, and silent secreting adenomas $(n=2$, one silent ACTHsecreting and one silent GH-secreting adenomas respectively); immunohistochemical data were missing in one case. In most cases, the index of cell proliferation was evaluated by immunohistochemical determination of the Ki-67 antigen using the MIB-1 monoclonal antibody (DBA Italia SpA, Milan, Italy), as previously described (Jaffrain-Rea et al. 2002). A dopamine agonist-treated PRL-secreting pituitary carcinoma and its dural metastasis, two additional untreated $\mathrm{GH}-$ secreting adenomas and five adamantinomatous craniopharyngiomas were available for immunohistochemistry only.

\section{RT-PCR analysis}

Total RNA was extracted with RNeasy Mini Kit (Qiagen s.p.A) according to the manufacturer's instructions. In order to remove any contamination by genomic DNA, DNase treatment was performed as an additional step before RNA elution and repeated before each retrotranscription step. RNA quality was equally preserved in snap-frozen and RNAlater-treated samples. First-strand cDNA synthesis was performed using $1 \mu \mathrm{g}$ total RNA in the presence of $50 \mathrm{U} \mathrm{MuLV}$ reverse transcriptase and random hexamers (Applied Biosystems, distributed by Applera Italia s.r.l, Monza, Italy). Briefly, RT-PCR amplification of target genes was performed using 150 ng equivalent RNA, in the presence of $0.5 \mathrm{pM}$ specific sense and antisense primers, $0.3 \mathrm{mM}$ dNTPs, $1.5 \mathrm{mM} \mathrm{MgCl} 2$ and $2.5 \mathrm{U}$ Gold Taq polymerase (Applied Biosystems) in a final volume of $50 \mu \mathrm{l}$, for a total of 35 cycles for pituitary factors and up to 45 cycles for bHLH factors respectively. Dimethyl sulfoxide (DMSO; 5\%) was added to the reaction mix for RT-PCR amplification of the Ngn1 gene. The pituitary factors Pit-1 and Tpit were used as cell-specific markers in order to exclude significant contamination of tumour samples by normal pituitary tissue. Primers for NeuroD1 and Pit-1 have been synthesised according to the previously reported sequences (Pellegrini et al. 1994, Ferretti et al. 2003 respectively), whereas primers specific for Ngn1, Ngn2 and Ngn 3 , and Tpit have been designed on the relative Genbank sequences (Table 1).

\section{Real-time PCR analysis}

The expression of bHLH transcripts was further studied by quantitative real-time RT-PCR (qRT-PCR) based on a Taqman methodology, using an ABI Prism 7700 Sequence Detection System (Applied biosystems, Applera Italia, Monza, Italy), and compared with $\beta$-actin expression. Ready-to-use gene expression assays were purchased from Applied Biosystems, 
Table 1 Primer sequences used for conventional RT-PCR analysis

Primers

$\begin{array}{ll}\begin{array}{l}\text { Gene; Genbank } \\ \text { access }\end{array} & \\ \text { Tpit } & \text { Forward } \\ \text { NM_005149 } & \text { Reverse } \\ \text { Ngn1 } & \text { Forward } \\ \text { BC028226 } & \text { Reverse } \\ \text { Ngn2 } & \text { Forward } \\ \text { AF303002 } & \text { Reverse } \\ \text { Ngn3 } & \text { Forward } \\ \text { AJ133776 } & \text { Reverse }\end{array}$

Oligonucleotide sequence

AGA ATG GCA GAC GGA TGT T

GTC CTC GGA GAC CCG AAT

CTT GAG ACC TGC ATC TCC GAC

GCG TTG TGT GGA GCA AGT CTT

GGT CTG GTA CAC GAT TGC AAA C

GCT GTT GGT GCA ACT CCA CGT

TCC AAG TGA CCC GTG AGA CG

TCC AGC GCG TAC AAG CTGT
PCR fragment length

(bp) with the following identification numbers: Hs_00159598 (NeuroD1), Hs_00246211 (Ngn1), Hs_00702774 (Ngn2), Hs_01875204 (Ngn3) and Hs_99999903 ( $\beta$-actin). Each reaction was performed in a final volume of $20 \mu \mathrm{l}$ with $80 \mathrm{ng}$ equivalent RNA, $1 \mu \mathrm{l}$ primers/fluorescent oligoprobe mix and $10 \mu \mathrm{l}$ UNG-universal mastermix (Applied Biosystems); for each bHLH factor assay, a $\beta$-actin assay was run on the same batch of cDNA. The thermal cycling conditions included $2 \mathrm{~min}$ at $50^{\circ} \mathrm{C}$, $10 \mathrm{~min}$ of denaturation at $95^{\circ} \mathrm{C}$, followed by 45 cycles of $95^{\circ} \mathrm{C}$ for $15 \mathrm{~s}$ and $60^{\circ} \mathrm{C}$ for $1 \mathrm{~min}$. All reactions were performed at least in duplicate.

\section{Immunohistochemistry}

Tissue sections were dewaxed in xylene and rehydrated through a descending ethanol series. Antigen retrieval was obtained by microwave boiling in citrate buffer ( $\mathrm{pH} 6 \cdot 0$ ) for 5,5 and $3 \mathrm{~min}$. Rabbit polyclonal antibodies directed against Ngn2 and Ngn3 were purchased from Chemicon (distributed by DBA Italia s.r.l, Segrate, Italy). Immunohistochemistry was performed using Ngn 2 and Ngn3 at a dilution of 1:200 and 1:50 respectively, with a multilink biotinylated antibody and the avidin-biotin peroxidase system according to manufacturer's instructions $\left(\mathrm{LSAB}^{+}\right.$kit, Dako Cytomation), introducing a blocking step for endogenous avidin and biotin activity. Co-localisation studies for Ngn2 and pituitary hormones were performed using prediluted mouse monoclonal antibodies for pituitary hormones (Dako Cytomation). For this purpose, a double step immunohistochemical study using the $\mathrm{LSAB}^{+}$kit (Marx et al. 1999) was designed to first detect cytoplasmic hormone using DAB as a chromogen, followed by a second step for the detection of nuclear Ngn2/3 using Novored as a chromogen (Vector, DBA Italia s.r.l). Blocking of endogenous peroxidase and avidinbiotin activities were performed at each step.

\section{Statistical analysis}

All data are expressed in mean \pm s.E.M., and statistical analyses were performed using a Statview 5.01 software (SAS Institute, Cary, NC, USA) for PC. For clarity of exposition, PRL-, GHand TSH-secreting adenomas, which show many similarities in bHLH expression profile, were grouped together as Pit-1 dependent, by opposition to the Pit-1-independent CNS and corticotroph PA. Because of the non-normal distribution observed for most parameters, non-parametric tests were used to compare or correlate continuous values (Mann-Whitney and Spearman tests respectively). Distribution of nominal values was compared by the $\chi^{2}$ test. The level of significance was set at $P<0 \cdot 05$.

\section{Results}

bHLH gene expression in the normal pituitary gland and in PAs

General results Table 2 shows $b H L H$ gene expression in normal pituitary (NP) samples and in PA according to RT-PCR and qRT-PCR respectively, and examples of RT-PCR experiments are shown in Fig. 1. Differences between RT-PCR and qRT-PCR results reflect the higher sensitivity

Table 2 Expression of NeuroD1 and neurogenin (Ngn) transcripts in the normal human pituitary and in pituitary adenomas

\begin{tabular}{|c|c|c|c|c|c|c|c|c|}
\hline & \multicolumn{2}{|l|}{ NeuroD1 } & \multicolumn{2}{|l|}{ Ngn1 } & \multicolumn{2}{|l|}{ Ngn2 } & \multicolumn{2}{|l|}{ Ngn3 } \\
\hline & RT-PCR & qRT-PCR & RT-PCR & qRT-PCR & RT-PCR & qRT-PCR & RT-PCR & qRT-PCR \\
\hline Normal pituitaries & $7 / 7(100 \%)$ & $7 / 7(100 \%)$ & 0/7 (0\%) & $1 / 7(14 \cdot 0 \%)$ & $4 / 7(57 \cdot 1 \%)$ & $7 / 7(100 \%)$ & $1 / 7(14 \cdot 0 \%)$ & $4 / 7(57 \cdot 1 \%)$ \\
\hline
\end{tabular}

RT-PCR, conventional RT-PCR; qRT-PCR, quantitative real-time RT-PCR. 

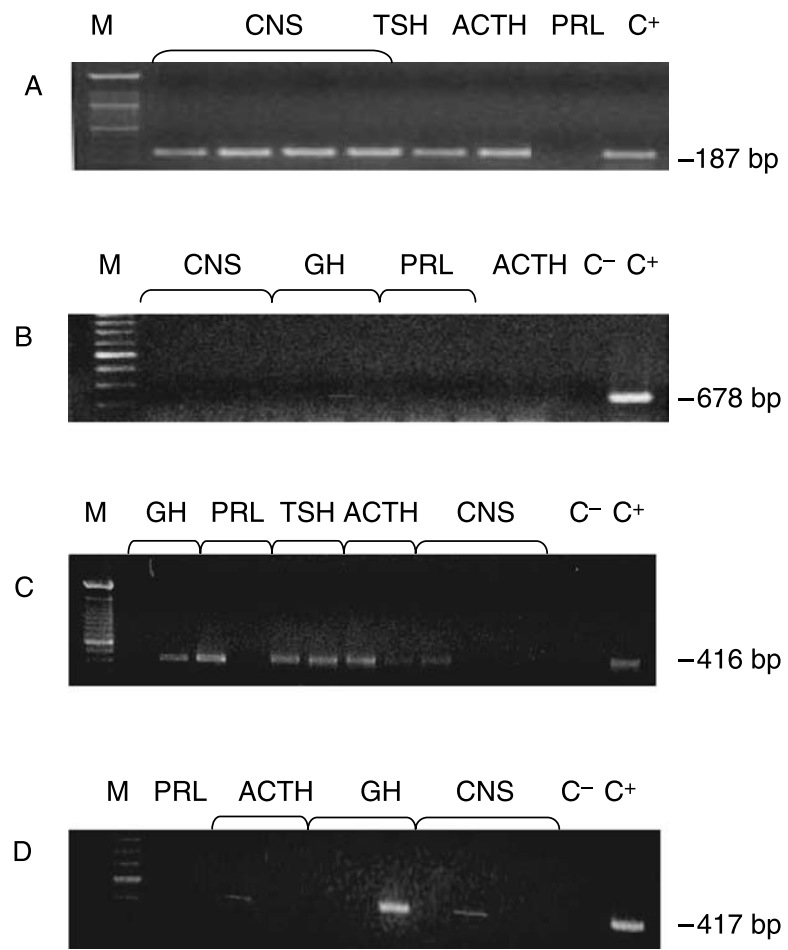

Figure 1 RT-PCR for bHLH transcription factors in pituitary adenomas. Shown are representative examples of RT-PCR for NeuroD1 (A), Ngn1 (B), Ngn2 (C) and Ngn3 (D) respectively. Data were obtained after 45 cycles of amplification and electrophoresis on a $1 \cdot 8 \%$ agarose gel. $M$, molecular weight marker; $\mathrm{C}^{-}$, negative controls; $\mathrm{C}^{+}$, positive controls; the phenotype of pituitary adenoma samples is indicated for each experiment.

of the latter methodology in samples expressing low transcript levels. Overall, NeuroD1 was observed in all NP and up to $84 \cdot 3 \%$ of PA respectively. Ngn2 was the most commonly expressed member of the Ngn family, being present in up to $4 / 6$ NP and $76 \cdot 5 \%$ of PA respectively, whereas Ngn 3 and Ngn 1 were detected in up to $30 \cdot 4$ and $9 \cdot 1 \%$ of PA respectively.

A preliminary study of $\beta$-actin transcripts was performed before the analysis of qRT-PCR data, indicating similar $C_{\mathrm{T}}$ levels in NP and PA $(22 \cdot 15 \pm 0 \cdot 30$ vs $22 \cdot 70 \pm 0 \cdot 40$ respectively, $P=0 \cdot 86$ ). PA tended to overexpress NeuroD1 and Ngn2 as compared with NP, though this was not statistically significant, due to the marked variability observed in PA $(P=0.25$ for NeuroD1 and $P=0.35$ for Ngn2 respectively). Overall, Ngn2 and NeuroD1 transcripts were inversely correlated $(P=0 \cdot 015)$; accordingly, NeuroD1 expression was lower in Ngn2-expressing PA $(P=0 \cdot 023)$. Where present, Ngn3 and Ngn1 were expressed at very low levels - 100- to 1000-fold less than NeuroD1 or Ngn2.

Analysis of qRT-PCR data according to PA phenotype Analysis of individual levels of NeuroD1, Ngn2 and $\mathrm{Ngn} 3$ transcripts revealed a differential expression of $b H L H$ genes according to PA phenotype (Fig. 2). Overexpression of
NeuroD1 could be observed in CNS and corticotroph PA, with very low levels of expression in Pit-1-dependent PA where detected. Accordingly, NeuroD1 expression was significantly higher in Pit-1-independent than in Pit-1dependent PA $(P=0 \cdot 001)$, especially when considering CNS adenomas only $(P=0.0008$ versus $P i t-1-$ dependent $P A)$. In contrast, overexpression of Ngn2 could be observed in Pit-1dependent and corticotroph PA, with very low levels in CNS adenomas where detected. Accordingly, Ngn2 expression was significantly higher in secreting than in CNS PA $(P=0 \cdot 007)$, especially when considering Pit-1-dependent PA only $(P=0 \cdot 0006$ versus CNS). Among CNS, only $1 / 5$ gonadotroph adenoma expressed detectable levels of Ngn2. The Ngn2/NeuroD1 ratio was $\geq 1$ in most Pit-1-dependent but only in a minority of Pit-1-independent PA expressing both factors (11/15 Pit-1 dependent, 1/11 CNS and 1/7 ACTHsecreting respectively, $\left.\chi^{2}=13 \cdot 3, P=0 \cdot 001\right)$.

Ngn3 tended to be preferentially expressed by secreting compared with CNS adenomas $(P=0 \cdot 09)$, especially by Pit1-dependent PA $(P=0.02$ versus CNS adenomas), but overexpression was exceptional. In all cases, the Ngn3/NeuroD1 ratio was remarkably low $(<0 \cdot 01)$. Very low levels of Ngn1 were detected in three secreting and one non-secreting PA respectively.

Analysis of qRT-PCR data according to other tumour characteristics Overall, no relationship was found between bHLH expression and any parameter of tumour aggressiveness such as tumour volume, invasiveness or Ki-67 index of cell proliferation (data not shown). Because of the differential expression of $b H L H$ genes, CNS and Pit-1dependent PA were then analysed as distinct subgroups. In CNS adenomas, NeuroD1 expression tended to be higher in invasive tumours $(P=0.058$ versus non-invasive), but no significant variation in either NeuroD1 or Ngn2 expression was found according to tumour volume or Ki-67 index (data not shown). In Pit-1-dependent PA, Ngn2 expression was unrelated to tumour volume or invasiveness, but tended to be lower in tumours expressing a Ki-67 index $\geq 3 \%(P=0 \cdot 12)$ and was significantly higher in those which received preoperative pharmacological treatment compared with those which did not $(P=0 \cdot 025)$. Despite the limited number of samples, similar trends were observed for prolactinomas treated with dopamine agonists and for somatotroph adenomas treated with somatostatin analogues compared with their untreated counterparts $(P=0.07$ and $P=0.12$ respectively). Ngn1 was expressed by two highly invasive and recurrent PA (one ACTH and one null cell respectively), and by two intrasellar-secreting adenomas treated with somatostatin analogues pre-operatively (one GH-secreting and one TSH-secreting respectively).

Expression of neurogenin proteins in the normal pituitary and in pituitary tumours Where present, Ngn2 immunopositivity was clearly restricted to the nucleus. 

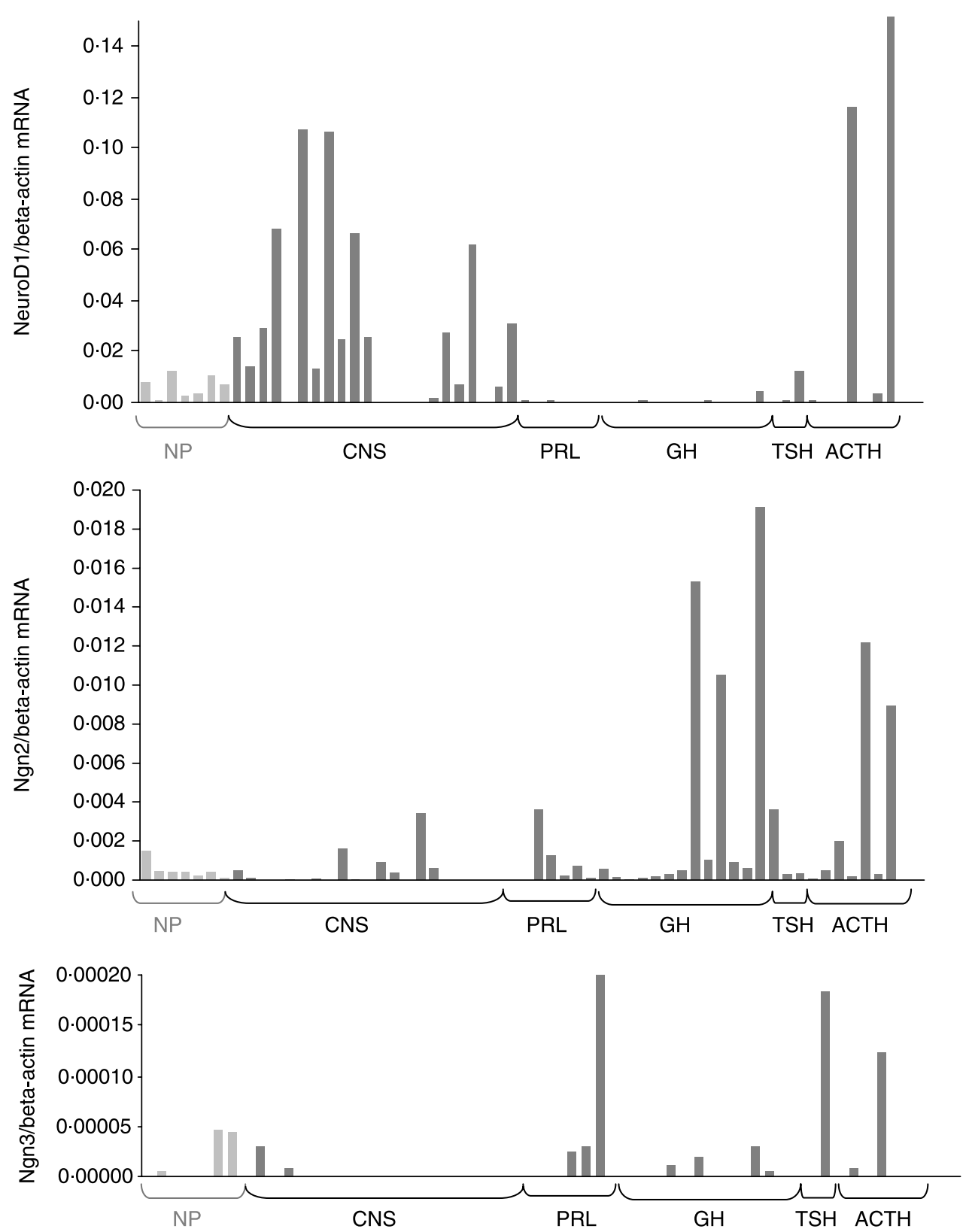

Figure 2 NeuroD1, Ngn2 and Ngn3 expression in the normal pituitary (NP) and in pituitary adenomas (PAs) according to qRT-PCR. Shown are individual levels of each factor observed in NP and in PA classified according to functional phenotype. Note the different scale used to show the very low levels of Ngn3 expression.

Data obtained in the NP are shown in Fig. 3. Ngn2 was observed in scattered cells of the adenohypophysis, in most cells of the pars intermedia, but not in the neurohypophysis. Co-localisation experiments showed Ngn2 expression in most secreting cells, with a predominance of corticotrophs and somatotrophs and the possible exception of gonadotrophs where no clear positivity could be documented. Ngn2 immunostaining was stronger in most pituitary tumours, including PA, the pituitary carcinoma and some craniopharyngiomas (Fig. 4A-E). Data obtained in 29 PA are summarised in Table 3. Ngn2 expression was diffuse in all ACTH- and in most GH- and PRL-secreting PA and focal in the two TSH-secreting and in most CNS PA where present. In somatotroph adenomas, Ngn2 immunopositivity was stronger in treated than in untreated cases. The pituitary PRL-secreting carcinoma and the corresponding dural 


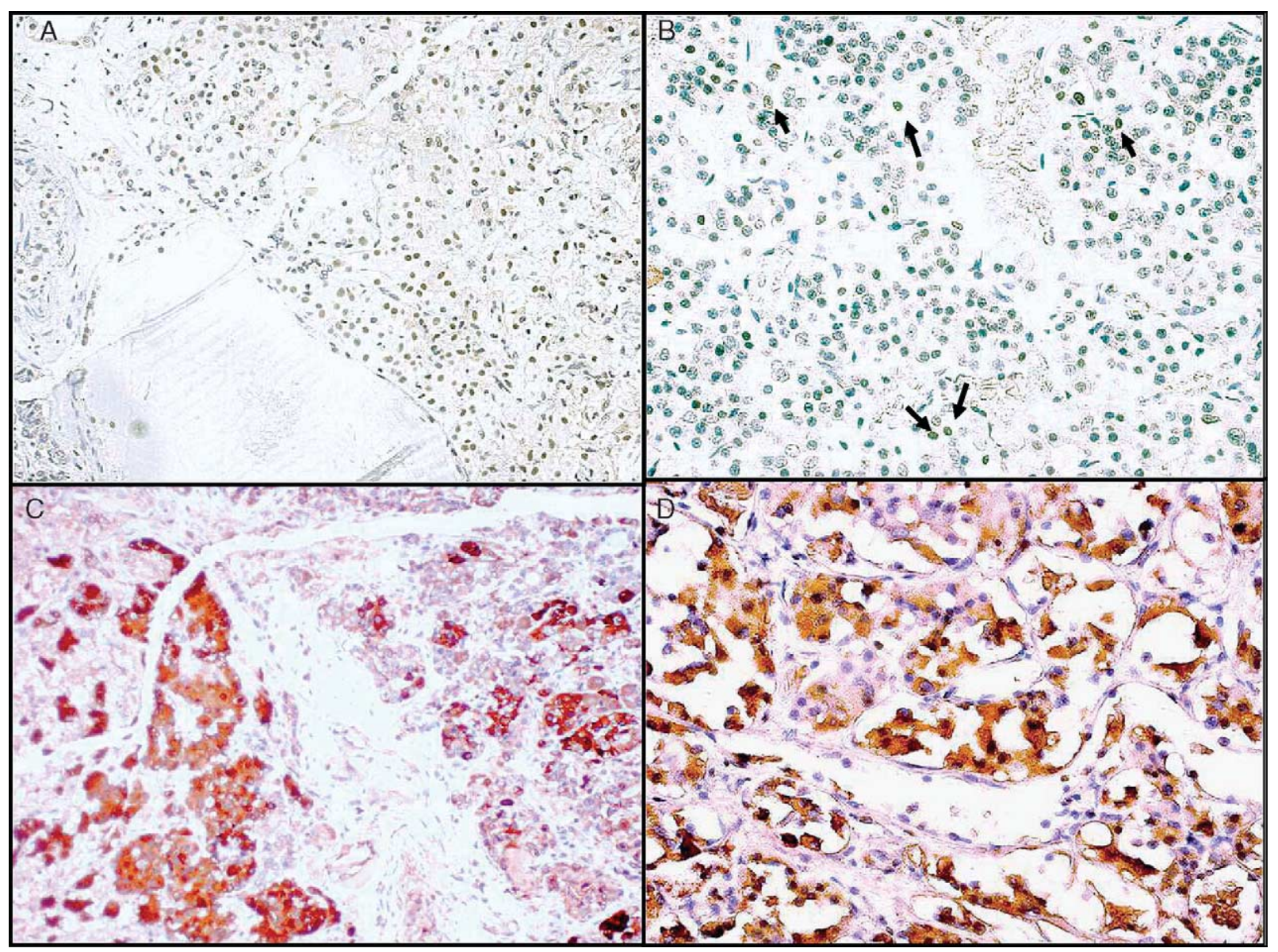

Figure 3 Expression of Ngn2 protein in the normal human pituitary. (A) A number of Ngn2 + nuclei are observed in the pars intermedia; (B) scattered nuclei with moderate staining for Ngn2 are observed in the anterior pituitary (examples are indicated by an arrow); (C) nuclear Ngn2 staining in ACTH cells (from left to right: pars intermedia, anterior pituitary); (D) nuclear Ngn2 staining in some GH-secreting cells. Magnification $20 \times(\mathrm{A}$ and $\mathrm{B})$ and $40 \times(\mathrm{C}$ and $\mathrm{D})$.

metastasis showed diffuse Ngn2 expression. Ngn2 immunostaining was also observed in the epithelial cells of craniopharyngiomas.

No nuclear Ngn3 protein could be detected in the NP, and a moderate positivity was observed in two treated GH-secreting out of the 11 PAs studied by immunohistochemistry (Fig. 4F), despite 10/11 expressed Ngn3 transcripts (two ACTH-, three CNS, three GH-, one PRL- and one TSH-secreting PAs respectively). The weak cytoplasmic positivity observed in most NP and PA was considered as likely artefactual, since it was present regardless of $\mathrm{Ngn} 3$ transcripts. The PRL-secreting PA and the corresponding dural metastasis were negative for Ngn3 immunostaining.

\section{Discussion}

This study shows for the first time that members of the neurogenin family can be expressed by normal and tumourous pituitaries, with a clear predominance of Ngn2.
While extending our previous findings in such tissues (Ferretti et al. 2003), it reveals an unexpected inverse relationship between $\mathrm{Ngn} 2$ and NeuroD1 in PA, reflecting a differential expression according to tumour phenotype.

The NeuroD1 expression profile observed in PA is consistent with previous reports (Oyama et al. 2001, Ferretti et al. 2003) and additional considerations can be made at the light of qRT-PCR data. Overexpression of NeuroD1 was more frequent in CNS than in corticotroph adenomas. As a corticotroph marker, a consistent overexpression could be expected in this latter subgroup, suggesting some degree of NeuroD1 downregulation in corticotroph adenomas, as reported in a neuroblastoma cell line (Chae et al. 2004). In CNS adenomas, the trend toward a higher expression of NeuroD1 in invasive tumours may be indicative of a developmental expression preceding corticotroph differentiation, with tumoural reactivation as a result of a relative dedifferentiation process (Ferretti et al. 2003). Alternatively, extracellular signals may induce NeuroD1 in these tumours. 


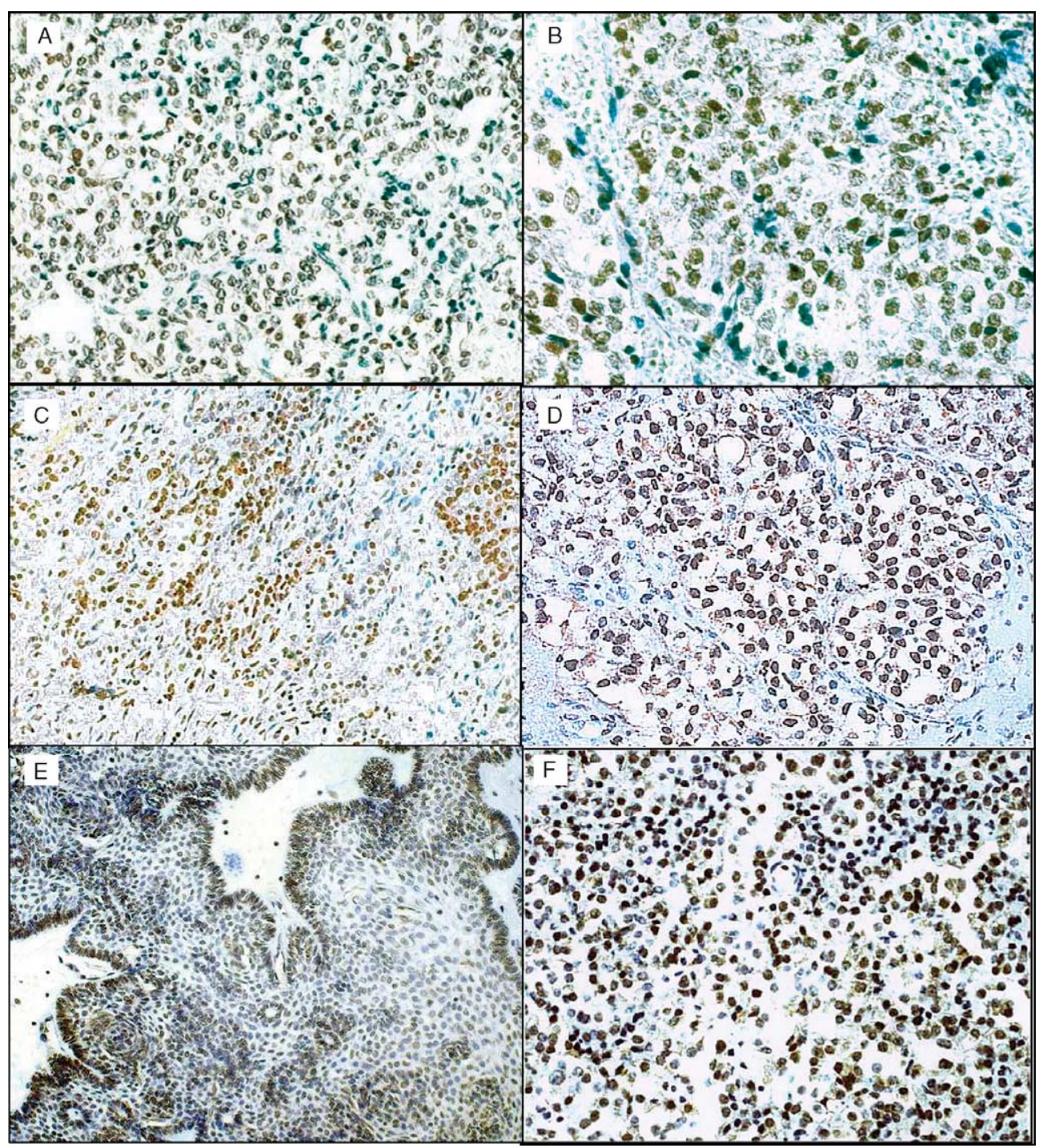

Figure 4 Expression of Ngn proteins in human pituitary tumours. (A-E) Nuclear immunostaining for Ngn2 (A) a $\mathrm{GH}$-secreting, (B) an ACTH-secreting and (C) a TSH-secreting pituitary adenomas respectively, in a dural metastasis from a PRL-secreting pituitary carcinoma (D) and in an adamantinous craniopharyngioma (E). (F) Immunostaining for Ngn3 in a GH-secreting adenoma. Magnification $20 \times(\mathrm{A}, \mathrm{C}$ and $\mathrm{E})$ and $40 \times(\mathrm{B}, \mathrm{D}$ and F).

Finally, the low levels of NeuroD1 expression observed in Pit1-dependent PA can explain previously discordant reports, based on differently sensitive methods (Oyama et al. 2001, Ferretti et al. 2003).

Ngn2 was detected in the NP, with a frequent overexpression in PA but significant variations according to tumour phenotype. Similar data were found at a protein level, with a stronger immunostaining in most PA and a nuclear localisation suggestive of biological activity. Ngn2 was expressed by corticotrophs of the pars intermedia and scattered cells of the adenohypophysis. Though no restricted phenotype specificity was observed, nuclear staining was more evident in somatotrophs and corticotrophs but unclear in gonadotrophs. A preferential expression of Ngn2 by secreting PA was found at both transcriptional and protein levels, with a diffuse immunopositivity in corticotrophinomas, somatotrophinomas and prolactinomas. Ngn2 immunostaining was focal in TSH-secreting adenomas and in some CNS adenomas, suggesting expression by a subset of adenomatous cells. This raises the issue of the possible role of Ngn2 in the pituitary. During mice ontogenesis, Ngn2 appears at the end of Rathke's pouch differentiation and turns off a few days later, and seems unrelated to corticotroph differentiation (Lamolet et al. 2004). The expression of Ngn2 by the normal adult pituitary is suggestive of a dual effect during ontogenesis, once as a precocious factor - data 
Table 3 Immunohistochemical detection of neurogenin 2 (Ngn2) in pituitary adenomas

\begin{tabular}{|c|c|c|c|c|c|c|c|c|}
\hline & & & & & & & & \\
\hline & Age/sex & $\begin{array}{l}\text { Clinical } \\
\text { presentation* }\end{array}$ & Adenoma $^{+}$ & Hormone & Ki-67\% & Ngn2 mRNA ${ }^{\S}$ & Positivity & Staining \\
\hline Cas & & & & & & & & \\
\hline 1 & $44 / F$ & Cushing & M & ACTH & $1 \cdot 0$ & + & ++ & $+/++$ \\
\hline 2 & $58 / F$ & Cushing & $\mathrm{m}$ & ACTH & nd & + & ++ & $+/++$ \\
\hline 3 & $61 / F$ & Cushing & $\mathrm{m}$ & ACTH & $1 \cdot 0$ & + & ++ & + \\
\hline 4 & $26 / F$ & Cushing & M-inv-ESS & ACTH & $5 \cdot 0$ & + & ++ & + \\
\hline 5 & $49 / F$ & Cushing & M-SSE & ACTH & $3 \cdot 0$ & + & ++ & + \\
\hline 6 & $66 / F$ & $\begin{array}{l}\text { CNS-subclinical } \\
\text { hypercortisolism }\end{array}$ & M-inv-SSE & ACTH-silent & $10 \cdot 0$ & ++ & +++ & $+1++$ \\
\hline 7 & $51 / \mathrm{F}$ & $\mathrm{CNS}$ & M-inv-SSE & $\mathrm{FSH} / \mathrm{LH}$ & $0 \cdot 5$ & + & Focal (+) & $+1-$ \\
\hline 8 & $68 / F$ & CNS & M-inv (R) & Null cell & $0 \cdot 5$ & - & - & - \\
\hline 9 & $60 / M$ & CNS & M-SSE & Null cell & $0 \cdot 0$ & + & - & - \\
\hline 10 & $67 / M$ & CNS & M-SSE & Null cell & nd & + & Focal $(+)$ & $+1-$ \\
\hline 11 & $16 / M$ & CNS & Giant & Null cell & $4 \cdot 0$ & ++ & Focal $(++)$ & + \\
\hline 12 & $64 / M$ & CNS & Giant (R) & Null cell & $0 \cdot 5$ & + & - & - \\
\hline 13 & $38 / M$ & CNS & M-SSE & Null cell & $3 \cdot 0$ & + & Focal $(+)$ & $+/++$ \\
\hline 14 & $57 / M$ & CNS & M-inv-SSE & Null cell & $1 \cdot 0$ & + & + & + \\
\hline 15 & $17 / F$ & CNS & M-SSE & GH-silent & $3 \cdot 0$ & ++ & ++ & $+/++$ \\
\hline 16 & $33 / F$ & Acromegaly $^{\top}$ & M-inv & $\mathrm{GH}$ & $1 \cdot 0$ & + & +++ & ++ \\
\hline 17 & $39 / F$ & Acromegaly $^{\top}$ & M & GH/PRL & nd & + & ++ & $+1++$ \\
\hline 18 & $61 / F$ & Acromegaly & $\mathrm{m}$ & $\mathrm{GH} /$ multi $\mathrm{H}$ & $0 \cdot 0$ & + & +++ & $+1++$ \\
\hline 19 & $53 / \mathrm{F}$ & Acromegaly & $\mathrm{m}$ & $\mathrm{GH}$ & nd & ++ & +++ & ++ \\
\hline 20 & $26 / F$ & Acromegaly & M-inv-SSE & $\mathrm{GH} / \mathrm{PRL}$ & $6 \cdot 0$ & + & + & + \\
\hline 21 & $43 / M$ & Acromegaly & M & GH/PRL & $3 \cdot 0$ & + & + & + \\
\hline 22 & $30 / M$ & Acromegaly & M-SSE & $\mathrm{GH}$ & $8 \cdot 0$ & nd & + & + \\
\hline 23 & $12 / \mathrm{M}$ & Gigantism & M & $\mathrm{GH} / \mathrm{PRL}$ & $15 \cdot 0$ & nd & $+1-$ & + \\
\hline 24 & 48/M & Prolactinoma & M-inv-SSE & PRL & nd & + & $+1-$ & $+1-$ \\
\hline 25 & $58 / F$ & Prolactinoma $^{\top}$ & M-inv & PRL & $1 \cdot 0$ & ++ & + & + \\
\hline 26 & $45 / F$ & Prolactinoma & Giant & PRL & $7 \cdot 0$ & + & ++ & $+1-$ \\
\hline 27 & $43 / F$ & Prolactinoma $^{\top}$ & M-inv-SSE & PRL & $5 \cdot 0$ & + & + & $+1-$ \\
\hline 28 & $48 / M$ & Hyperthyroidism $^{\top}$ & M & TSH & $0 \cdot 5$ & + & $\begin{array}{l}\text { Focal } \\
\qquad(+++)\end{array}$ & ++ \\
\hline 29 & $28 / F$ & $\begin{array}{l}\text { Previous } \\
\text { hyperthyroidism } \\
\text { (thyroidectomy) }^{\mathrm{T}}\end{array}$ & M & TSH/multiH & $0 \cdot 5$ & ++ & $\begin{array}{l}\text { Focal } \\
\qquad(+++)\end{array}$ & ++ \\
\hline
\end{tabular}

${ }^{*} \mathrm{~T}$, pre-operative pharmacological treatment; ${ }^{\dagger} \mathrm{m}$, microadenoma; $\mathrm{M}$, macroadenoma; inv, invasive; SSE, suprasellar extension; $(\mathrm{R})$, recurrent; nd, not done; ${ }^{\ddagger}$ according to qRT-PCR; data are quoted as follows: - , negative; + , in the normal pituitary range (mean \pm 2 s.D.);,++ overexpression $\left(>2\right.$ s.D.); ${ }^{\S}$ IHC was quoted as follows: positivity, $+/-<10 \% ;+10-30 \% ;++30-60 \% ;+++>60 \%$ of adenoma cells; and intensity, $+/-$ faint; + moderate; ++ intense respectively.

obtained in craniopharyngiomas arising from Rathke's pouch may support this hypothesis - and thereafter during final cell differentiation, possibly contributing to maintain a differentiated secreting phenotype. Other precocious developmental factors - Pitx factors, Hes $x 1$, PROP-1, have already been observed in normal adult and adenomatous pituitaries (Nakamura et al. 1999, Pellegrini-Bouiller et al. 1999, Mantovani et al. 2006). The preferential expression of Ngn2 in secreting PA appears to be related to tumour phenotype rather than to tumorigenesis itself for a series of reasons: (1) $\mathrm{Ngn} 2$ expression is unrelated to tumour volume or aggressiveness; (2) its lower expression in CNS adenomas may reflect the common gonadotroph origin of these tumours (Gittoes 1998) - indeed - the lowest expression was found in gonadotroph adenomas; (3) the highest levels of Ngn2 in CNS were observed in two silent secreting CNS and (4) the higher expression of Ngn2 in Pit-1-dependent PA which received pre-operative pharmacological therapy suggests that the control of mammosomatotroph cell proliferation is associated with Ngn2 expression-accordingly, Ngn2 expression tended to be lower in Pit-1-dependent PA expressing a high Ki-67 index. This point would deserve further investigation.

Ngn3 transcripts were observed at very low levels in some NP samples and in about $30 \%$ of PA, with a preferential expression in secreting PA. Nuclear Ngn3 protein was found in a minority of GH-secreting PA. Thus, though all but one Ngn3-positive adenoma also expressed NeuroD1, the Ngn3NeuroD1 pathway does not seem to play a significant role in pituitary tumours. Its possible role in pituitary ontogenesis is even more incertain, since no Ngn3 protein was observed in the developing mouse pituitary (Lamolet et al. 2004). At the moment, neuroendocrine cells clearly dependent on Ngn3 for NeuroD1 induction during development are limited to 
the gastroenteropancreatic tract, which is of endodermal origin (Gradwohl et al. 2000). However, no overexpression of Ngn3/NeuroD1 has been observed in gastrointestinal carcinoid tumours (Nakakura et al. 2005).

Very low levels of Ngn1 transcripts were detected in $<10 \%$ of normal and PA samples. Ngn1 has a preferential neural expression (Cau et al. 2002, Ross et al. 2003) and no Ngn1 protein was observed in the normal developing mouse (Lamolet et al. 2004). Thus, despite NeuroD1 was also expressed by Ngn1-expressing adenomas, the Ngn1-NeuroD1 pathway in neuroendocrine cells appears to be limited to a subset of neural crest-derived cells (Greenwood et al. 1999, Ma et al. 1999) and is unlikely to play a significant role in the pituitary.

In conclusion, Ngn2 is normally expressed in the human adult pituitary and can be overexpressed by secreting PA. Ngn2 is unlikely to account for NeuroD1 overexpression, which is prevalently observed in non-secreting PA. Though we cannot exclude downregulation of Ngn 2 by NeuroD 1 in this latter case, it is likely that both factors are differentially regulated in pituitary tumour cells. Possible links between Ngn2 expression and the control of cell proliferation by pharmacological treatment of secreting PA would deserve further investigation.

\section{Acknowledgements}

We thank Dr Remo Bernabei and Morena Sarra for excellent technical assistance. The authors declare that there is no conflict of interest that would prejudice the impartiality of this scientific work.

\section{Funding}

This study was partially supported by grants from MIUR, Ministero della Salute, Neuromed (IRCCS), Pozzilli and 'Carlo Ferri' Foundation, Monterotondo, Italy.

\section{References}

Cau E, Casarosa S \& Guillemot F 2002 Mash1 and Ngn1 control distinct steps of determination and differentiation in the olfactory sensory neuron lineage. Development 129 1871-1880.

Chae JH, Stein GH \& Lee JE 2004 NeuroD: the predicted and the surprising. Molecules and Cells 18 271-288.

Cho JH, Kwon IS, Kim S, Ghil SH, Tsai MJ, Kim YS, Lee YD \& Suh-Kim H 2001 Overexpression of BETA2/NeuroD induces neurite outgrowth in F11 neuroblastoma cells. Journal of Neurochemistry 77 103-109.

Dasen JS \& Rosenfeld MG 2001 Signaling and transcriptional mechanisms in pituitary development. Annual Reviews of Neuroscience 24 327-355.

Edlund H 1999 Pancreas: how to get there from the gut? Current Opinion in Cell Biology 11 663-668.

Ferretti E, Di Stefano D, Zazzeroni F, Gallo R, Fratticci A, Carfagnini R, Angiulli S, Santoro A, Minniti G, Tamburrano G et al. 2003 Human pituitary tumours express the bHLH transcription factors NeuroD1 and ASH1. Journal of Endocrinological Investigation 26 957-965.
Gittoes JL 1998 Current perspectives on the pathogenesis of non-functioning pituitary tumours. Journal of Endocrinology 157 177-186.

Gradwohl G, Dierich A, LeMeur M \& Guillemot F 2000 Neurogenin3 is required for the development of the four cell lineages of the pancreas. PNAS 97 1607-1611.

Greenwood AL, Turner EE \& Anderson DJ 1999 Identification of dividing, determined sensory neuron precursors in the mammalian neural crest. Development 126 3545-3559.

Huang HP, Liu M, El-Hodiri HM, Chu K, Jamrich M \& Tsai MJ 2000 Regulation of the pancreatic islet-specific gene BETA2 (NeuroD) by neurogenin3. Molecular and Cellular Biology 20 3292-3307.

Ito T, Udaka N, Yazawa T, Okudela K, Hayashi H, Sudo T, Guillemot F, Kageyama R \& Kitamura H 2000 Basic helix-loop-helix transcription factors regulate the neuroendocrine differentiation of fetal mouse pulmonary epithelium. Development 127 3913-3921.

Ivanova A, Liao SY, Lerman MI, Ivanov S \& Stanbridge EJ 2005 STRA13 expression and subcellular localisation in normal and tumour tissues: implications for use as a diagnostic and differentiation marker. Journal of Medical Genetics 42 565-576.

Jackson SM, Barnhart KM, Mellon PL, Gutierrez-Hartmann A \& Hoffler JP 1993 Helix-loop-helix proteins are present and differentially expressed in different cell lines from the anterior pituitary. Molecular and Cellular Endocrinology 96 167-176.

Jaffrain-Rea ML, Di Stefano D, Minniti G, Esposito V, Bultrini A, Ferretti E, Santoro A, Faticanti Scucchi L, Gulino A \& Cantore G 2002 A critical reappraisal of MIB-1 labelling index significance in a large series of pituitary tumors: secreting versus non secreting adenomas. Endocrine Related Cancer 9 103-113.

Kim S, Ghil SH, Kim SS, Myeong HH, Lee YD \& Suh-Kim H 2002 Overexpression of neurogenin1 induces neurite outgrowth in F11 neuroblastoma cells. Experimental and Molecular Medicine 34 469-475.

Kwok WK, Ling MT, Lee TW et al. 2005 Upregulation of TWIST in prostate cancer and its implication as a therapeutic target. Cancer Research $\mathbf{6 5}$ 5153-5162.

Lamolet B, Pulichino AM, Lamonerie T, Gauthier Y, Brue T, Enjalbert A \& Drouin J 2001 A pituitary cell-restricted T box factor, Tpit, activates POMC transcription in cooperation with Pitx homeoproteins. Cell 104 849-859.

Lamolet B, Poulin G, Chu K, Guillemot F, Tsai MJ \& Drouin J 2004 Tpitindependent function of NeuroD1(BETA2) in pituitary corticotroph differentiation. Molecular Endocrinology 18 995-1003.

Lanigan TM, DeRaad SK \& Russo AF 1998 Requirement of the Mash-1 transcription factor for neuroendocrine differentiation of thyroid $\mathrm{C}$ cells. Journal of Neurobiology 34 126-134.

Ma Q, Fode C, Guillemot F \& Anderson DJ 1999 Neurogenin1 and neurogenin 2 control two distinct waves of neurogenesis in developing dorsal root ganglia. Genes and Development 13 1717-1728.

Mantovani G, Asteria C, Pellegrini C, Bosari S, Alberti L, Bondioni S, Peverelli E, Spada A \& Beck-Peccoz P 2006 HESX1 expression in human normal pituitaries and pituitary adenomas. Molecular and Cellular Endocrinology 247 135-139.

Marx L, Arck P, Kapp M, Kieslich C \& Dietl J 1999 Leukocyte populations, hormone receptors and apoptosis in eutopic and ectopic firts trimestre human pregnancies. Human Reporduction 14 1111-1117.

Massari ME \& Murre C 2000 Helix-loop-helix proteins: regulators of transcription in eucaryotic organisms. Molecular and Cellular Biology 20 429-440.

Nakakura EK, Sriuranpong VR, Nakakura EK, Sriuranpong VR, Kunnimalaiyaan M, Hsiao EC, Schuebel KE, Borges MW, Jin N, Collins BJ et al. 2005 Regulation of neuroendocrine differentiation in gastrointestinal carcinoid tumour cells by Notch signaling. Journal of Clinical Endocrinology and Metabolism 90 4350-4356.

Nakamura S, Othsuru A, Nakamura S, Ohtsuru A, Takamura N, Kitange G, Tokunaga Y, Yasunaga A, Shibata S \& Yamashita S 1999 Prop-1 gene expression in human pituitary tumours. Journal of Clinical Endocrinology and Metabolism 84 2581-2584. 
Oyama K, Sanno N, Teramoto A \& Osamura RY 2001 Expression of Neuro D1 in human normal pituitaries and pituitary adenomas. Modern Pathology 14 892-899.

Pellegrini I, Barlier A, Gunz G, Figarella-Branger D, Enjalbert A, Grisoli F \& Jaquet P 1994 Pit-1 gene expression in the human pituitary and pituitary adenomas. Journal of Clinical Endocrinology and Metabolism 79 189-196.

Pellegrini-Bouiller I, Manrique C, Gunz G, Grino M, Zamora A, FigarellaBranger D, Grisoli F, Jaquet P \& Enjalbert A 1999 Expression of the members of the Ptx family of transcription factors in human pituitary adenomas. Journal of Clinical Endocrinology and Metabolism 84 2212-2220.

Pogoda HM, von der Hardt S, Kramer C, Schwarz H \& Hemmerschmidt M 2006 The proneural ascl1 is required for endocrine differentiation and cell survival in the zebrafish adenohypophysis. Development 133 1079-1089.

Poulin G, Turgon B \& Drouin J 1997 NeuroD1/BETA2 contributes to cellspecific transcription of the POMC gene. Molecular and Cellular Biology 17 6673-6682.

Poulin G, Lebel M, Chamberland M, Paradis FW \& Drouin J 2000 Specific protein-protein intrection between basix helix-loop-helix transcription factors and homeoproteins of the Pitx family. Molecular and Cellular Biology 20 4826-4837.
Ross SE, Greenberg ME \& Stiles CD 2003 Basic helix-loop-helix factors in cortical development. Neuron 39 13-25.

Rostomily RC, Bermingham-Mc Donogh O, Berger MS, Tapscott SJ, Reh TA \& Olson JM 1997 Expression of neurogenic basic helix-loop-helix genes in primitive neuroectodermal tumors. Cancer Research 57 3526-3531.

Semenza GL 2002 Involvement of hypoxia-inducible factor 1 in human cancer. Internal Medicine 41 79-83.

Söderholm H, Ortoft E, Johansson I, Ljungberg J, Larsson C, Axelson H \& Pahlman S 1999 Human Achaete-scute homologue 1 (HASH1) is downregulated in differentiating neuroblastoma cells. Biochemical and Biophysical Research Communications 256 557-563.

Wilson CB 1984 A decade of pituitary microsurgery: The Herbert Olivecrona Lecture. Journal of Neurosurgery 61 814-833.

Received in final form 17 May 2007

Accepted 4 June 2007

Made available online as an Accepted Preprint 13 June 2007 